\title{
THE USE OF ACTION RESEARCH AS AN APPROPRIATE METHOD OF INTRODUCING AND EVALUATING CHANGE IN NURSING CARE IN AN ACCIDENT \& EMERGENCY UNIT IN DURBAN - PART 2
}

\author{
D Kerr
}

\begin{abstract}
This 2-part article discussed firstly in Curationis 19.3 this year, the general characteristics of action research, compares several strategies of approach and describes the author's chosen method of applying action research to particular aspects of nursing care in an Accident \& Emergency Unit in a Durban hospital.
\end{abstract}

This second part describes identification of problems within the unit, the implementation of change and the limitations and potential of such study to nursing practice.

\section{INTRODUCTION}

According to the World Health Organisation, the number of global deaths attributed to unnatural causes (of which almost all are due to trauma) is $5.2 \%$. However, according to van der Spuy (1993), South Africa's figure for unnatural deaths is $16 \%$ or higher. In the United States, trauma is the fourth largest cause of death for all age groups (Emergency Nurses Association, 1991), whereas in South Africa, as van der Spuy (1993) and van der Merwe (1991) point out, it is rated second only circulatory conditions rate higher, and this is only because deaths due to stroke are included in this category. What is of concern is the loss of productive lives, especially those between the ages of fifteen and thirty years.

The extremely high mortality and morbidity rates in South Africa has led to an increase in the number of patients using Accident and Emergency (A \& E) Units. It is of note that an article discussing trauma in the South African community, van der Merwe states that "according to statistical data one third of trauma victims in the RSA are being treated in rural hospitals and only two thirds are admitted to hospitals with specific trauma facilities" (1991, 325).

\section{PROBLEM STATEMENT}

The political changes which have occurred in South Africa over the last few years have led to an escalation in fighting between rival factions and to displacement of people from rural areas into the towns.

The processes of industrialisation and urbanisation experienced in the greater Durban area recently have led to a population closely approaching 4 million people, that is half the population of KwaZulu-Natal (Dimopoulos and Owen, 1993). Large numbers of people have moved into and are living in formal and informal settlements. A number of the informal settlements in which they live are situated on unsafe land that is often deemed unsuitable for housing by the authorities as they are prone to rockfall and washaways.

The pattern of transportation also has changed in recent years. Minibus taxis are viewed by a large proportion of the population as being the quickest and most reliable transport even though they are largely responsible for the increasing motor vehicle collision rate and have been involved in violent taxi wars Dimopolous and Owen (1993) mention how the emergence of large numbers of minibus taxis has increased the demand on emergency services in the KwaZulu-Natal region. They point out that instead of Accident and Emergency staff caring for one injured patient, multiple accident victims now need to be attended at the same time

There has been no increase in the trauma facilities available to patients in the provincial hospitals in South African over the last ten to twenty years (van der Spuy, 1990) which is partly due to the economic recession and the decreased health budget. The existing facilities are being swamped, not only with serious trauma cases, but with large numbers of patients with relatively minor injuries. This increases the stress on a system that is already battling to cope.

Nursing staff working in these units have to treat severely injured patients, many of whom require care that the nurse is not capable of rendering due to the lack of specialised training in this field. Emotional and psychological effects on nurses, who are expected to deal with numbers of maimed and severely injured people and anxious relative, are substantial.

This is compounded by the fact that although the patient load has increased, there has not been a reciprocal increase in nursing staff allocated to A \& E units in hospital.

The number of people requiring treatment at any one time is unpredictable but the majority of incidents occur outside of office hours, that is between $17 \mathrm{h00}$ and $08 \mathrm{hO0}$ and over weekends and public holidays (van der Spuy, 1993; Dimopoulos and Owen, 1993). This has implications for those staffing the units and for those requiring treatment as they are often subjected to protracted waiting periods.

All these factors contribute to A \& $E$ units in the greater Durban area being stressful areas in which to work and may result in patient care being compromised.

In such high stress units, with little or no research culture, it is difficult to initiate scientific investigation of practice. Staff feel overburdened and see little space for research in this environment but research is necessary in this area of nursing practice as in any other

If traditional research is done by outsiders, it is questionable whether it will be readily implemented. Stressed systems are resistant to change, using routine as a defence mechanism. The action research approach seems a useful way in which the problems of both research and implementation can be addressed.

\section{Aim of the study}

The aim of this study was to explore how the use of an action research approach can improve the quality of nursing in an $A$ \& $E$ unit. (A brief introduction to the nature of action research, the research design chosen for the present study and ethical considerations peraining to the research were discussed in Part One of this article). 


\section{Research objectives}

a) To describe current nursing practice in an Accident and Emergency Unit.

b) To facilitate and describe the change process.

c) To describe outcomes in terms of patients, organisations and nurses.

d) To evaluate the production of knowledge via this research approach.

\section{Selection of the unit}

The criteria used when choosing the unit to conduct the research were that the unit would be utilised by whoever required urgent medical or surgical treatment and that the facility would be open twenty four hours a day. It was felt that the researcher should be able to understand most of what was said by both the patients and staff in the unit and English therefore was the language of choice. A large patient population or turnover of patients was seen as being an important criterion. The manager of a local private hospital with a "trauma unit" which provides emergency care for all sectors of the population granted permission for the study to be conducted following consultation with the matron of the hospital and the registered nurse in charge of the unit.

\section{Data Collection}

Data were collected by the researcher twice during the study. Initially baseline data were gathered which the participants used to identify problems and issues which had arisen during this period. Once the participants felt that change had occurred, the researcher embarked on a further period of data collection.

The 'participant comprehension' approach was used to gather data, a term used by Collins in 1984 to describe a method of collecting data while at the same time appreciating what it was like working on a unit.

He pointed out that a participant observer has to take on a role and make notes as unobtrusively as possible. In contrast, participant comprehension allows the researcher to enter the field with the participants fully aware of the purpose of the research. This solves the ethical and methodological problems of deception and dissimulation which inherently face the participant observer (Webb, 1989). The researcher planned to do as Webb $(1989,405)$ did in her study, that is "to work alongside trained nurses on their own ward and use my nursing and teaching experience to help them to evaluate their practice, plan and implement change and evaluate its effects".

A problem was that no "red code" seriously-injured patients were admitted to the unit during the author's first few days there.
With the unit staff, the admission book was looked at and the patients admitted to the unit most frequently were found to be those who had taken overdoses.

It then was decided that the care and treatment of these patients would be observed carefully. While waiting for people who had taken overdoses to be admitted, the researcher observed the staff's interaction with children who had taken accidental overdoses and also with other categories of patients. Eventually the admissions of four patients who had taken overdoses and three 'red code' patients formed the baseline observations.

\section{Identification of Problems}

Having completed the first observation phase, dates were set for the researcher to meet with each shift to discuss the problems and issues that had arisen during this period. The researcher was asked to meet with the nursing staff during their on-duty time when they were not busy working with patients. This was agreed to although it made finding mutually suitable times quite difficult.

Several themes were identified which are discussed in the following paragraphs.

\section{Theme 1: Self destructive behaviour}

Three of the four shifts agreed that there was a problem regarding their attitude to people who had deliberately tried to harm themselves by taking an overdose. Most of the nursing staff felt that when they were really busy with other patients who had been injured "through no fault of their own" and "who really wanted to live", caring for a patient who had taken an overdose took a valuable pair of hands away from the other patients.

They all agreed that their attitude towards overdose patients often depended on how busy they were (or had been) on the unit when such a patient was admitted. They said that their own previous life and work experiences influenced their attitudes a great deal. Many of them mentioned that they found overdose patients to be "manipulative", "difficult" and "attention seeking". They mentioned that what they found to be most frustrating was the readmission of the same patient week after week following a similar or different type of overdose attempt. They said that overdose patients were sometimes verbally and physically aggressive towards them and that this was compounded when the patient's relatives or friends were abusive too.

It was said too, that at times the overdose patient was so drowsy that they did not know where they were, did not recognise anyone and had no recollection of anything that happened to them while they were in the unit, that the nurses felt it was better to "just get on and look after them physically and let the ward do everything else for them".
One said that she "hates looking after them, giving them Ipecac and watching them puke in a bucket". She could not understand why they do it and "why they don't get their lives together".

Another said that she is a perfectionist and that overdose patients tend to make her feel that she has not done her job properly and that there were still things that she should have done.

A number of the nursing staff said that often there was no chance to talk to the patient to find out why they had taken an overdose and that if they knew, they would be able to relate better to the patient.

They all agreed that they were far more supportive of children who had taken accidental overdoses and that they spent a great deal of time speaking to and reassuring the parents of these children. The children are generally given a fluffy toy to hold onto while they are being treated and they are allowed to take this toy home. This is to make their hospital experience less traumatic. The staff pointed out that caring for a person who had taken an accidental overdose is very different from caring for a person who had deliberately tried to harm himself.

\section{Divergent theme: Difficult relatives}

The nursing staff said that they had a problem working with difficult relatives, and that they sometimes did not know what to say to relatives in certain circumstances (eg when a patient was critically ill or when relatives accused them of not doing their job properly).

\section{Divergent theme: Breaking bad news}

A few of the nursing staff said that they experienced difficulty breaking bad news, such as the death of a husband or child, to relatives. This was compounded by the fact that there was no suitable private place in which to break news like this.

\section{Theme 2: Recording observations and treatment}

They agreed that there was a problem regarding recording observations and treatment in that entries were not always entered chronologically and often observations, treatments and procedures performed on the patient were not documented at all. They felt that the reason for this was that they were usually doing the next thing for the patient and recording what they had done was of secondary importance. They agreed that it was important, but felt that it took valuable time away from the patient. especially when resuscitating or treating a patient admitted to the A \& E unit.

\section{Planning of change or 'Moving'}

The researcher asked each shift about the type of input they felt they needed. It was suggested that a folder of readings be made up 
and left on the unit for the staff to read and discuss. A mutually convenient time would then be arranged for the researcher to join the nursing staff to discuss various aspects of the readings and how they might influence practice.

This proved to be challenging. Some of the problems encountered were that the times the researcher arrived to talk to the nursing staff were not always appropriate.

During this time too, the researcher asked the nursing staff to complete a simple attitude scale concerning their attitudes to people who had taken overdoses. This was based on articles written by Ghodse, Ghaffari, Bhat, Galea and Qureshi (1986) and Reilly, Ray, Day, Wodak, O'Connor and Thompson (1987). The underlying purpose was to enable nurses to establish where their own personal biases lay, to establish common ground, to provide information that might help them decide on which areas they wanted to focus their discussions and to provide baseline information for comparison gleaned at the end of the study to see whether any change in attitude had occurred. Attitudes of the nursing staff varied accordingly to patients who had taken a genuine accidental overdose or who had failed to comply with the prescription for medication, those who had taken an overdose in response to a stressful situation, those who had taken an overdose as a suicidal gesture to influence others, those who had taken an overdose where alcoholism and compulsive drug use might have contributed towards the behaviour and finally those who had taken an overdose while psychotic.

They were not surprised at the results of this small survey and the majority were keen to discuss the reasons behind their biases. It also encouraged them to read the articles and to compare their attitudes with those of the respondents in the studies by Ghodse et al (1986) and Reilly et al (1987). Many hours were spent talking to the nursing staff during this period, both formally and informally. During this time the researcher became aware that nurses need a great deal of support especially from people or even animals outside of the work environment. When this is not available or the relationship is threatened for any reason, they find it difficult to be caring towards other people.

Occasionally a staff member actively worked against the research process. Such attitude and behaviour sometimes influenced others within the group and the researcher had to work extremely hard to re-establish relationships and maintain their interest in the research process by pointing out what a difference they were already making with regard to looking after overdose patients and by acknowledging that change is not easy This happened four times during this phase of the research process. Initially this was found disheartening, especially as it was usually only one individual who seemed to have a problem with the process, and yet that individual was able to exert a great deal of influence over the others within the group. However, the researcher came to realise that this was a part of the process and that it was usually related to other processes occurring within the unit and hospital environment at the same time; it was often easier for the individual to find fault with the research than it was for her to change or exert influence on the other parts of the system which were frustrating her.

\section{Implementation of change}

\section{Patients who have taken overdoses}

After reading the literature provided by the researcher and after having discussed with the researcher, possible ways of improving their care and interaction with overdose patients and their relatives and friends, the staff decided that they would then try and implement some of the planned changed behaviour with the next patient who arrived in the unit. The researcher pointed out to them that the second phase of observation would not begin until they felt comfortable for it to happen.

This process took several months and many hours of discussion; other problems associated with caring for overdose patients emerged. such as working with abusive patients and relatives, coping with the sudden death in the unit and the breaking of bad news to relatives. It became evident that the nursing staff needed to have access to some form of critical incident stress debriefing, a function that the researcher was performing during the study.

The staff were very critical of their own behaviour and were keen to do things "properly". While this was encouraging, they became frustrated because the patients continued to be abusive and demanding and did not seem to respond to their increased effors to be supportive and understanding.

The researcher drew up a protocol (based on information from the literature, discussions with colleagues involved with psychosocial support to people who are distressed and on discussions with the nursing staff in the unit) for them to use when overdose patients were admitted.

They tried using it when the next overdose patient was admitted and were pleased with the results. They said that the patient seemed to respond well to the phrases that they used and that they felt less frustrated and that they were meeting the patients needs.

\section{Recording observations and treatment}

The researcher took various charts acquired during visits to $A$ \& $E$ units in England and Northern Ireland a couple of months previously as well as other charts published in the Journal of Emergency Nursing. to the unit. Staff then used ideas from these charts to draw up a char that would work well in their unit.
They included the two doctors who worked in the unit full time during the week in the planning of the document and came up with a prototype that reflected observations and interventions performed by both the doctors and the nurses on the unit.

The researcher was not directly involved in compiling the new chart at any stage. The finished document was presented to her as a fait accompli approximately two weeks after discussions concerning problems with the old chart.

\section{Second phase of data collection}

After several months it was decided that the second phase of data collection should begin. This was not easy as it was extremely difficult to be available when overdose patients were admitted to the unit as there is often no waming when such a patient is to be admitted. The staff also have to start resuscitating patients as soon as they arrive and found it difficult to contact the researcher at work or at home. She therefore decided to spend evenings and weekends in the unit, but was faced with the moral dilemma of waiting for someone to take an overdose so that data could be collected. She eventually observed the admission of 6 patients who had taken overdosage.

The second phase of observation and feed-back from the nursing staff showed that some behavioral and attitudinal change had occurred. They were asked to complete the same attitudinal scale regarding their attitudes towards different categories of overdose patients to determine if there had been any change. However, it was not possible to correlate the results with those of the first response as different staff members had completed the scales on the two separate occasions.

\section{"Refreezing"}

The third and final stage of the research process referred to as "refreezing" occurs when the nursing staff show that their behaviours and attitudes have changed and these changes appear to be self-sustaining ie the newly acquired behaviour has been integrated into the participants' personalities (Bowman, 1986). The research project is then terminated and the researcher withdraws from the unit.

The second phase of observation and feedback from staff showed that some behavioral and attitudinal change had occurred. Most of the nursing staff who had been involved in the research process had found it to be worthwhile and said that they were committed to re-evaluating the forms used for charting patient data on a regular basis. They also said that they felt more satisfied with the way they cared for patients who had deliberately tried to harm themselves. They thought that the patients themselves, and often their relatives and friends had benefitted from their increased 
understanding of the different factors leading to this type of behaviour. They said that these factors had also inadvertently led to improved physical care of the overdose patient.

\section{Factors facilitating the change process}

Cope (1981) states that factors such as power and influence are important factors which modify change. He also mentions that compliance, identification and internalisation play an important psychological role in the manner in which an individual adjusts. Compliance usually results in the person doing something grudgingly. Identification with or admiration of a person can result in change but this change usually remains dependent on the continued presence and influence of the charismatic source. Internalisation, where the person adopts an idea as their own and internalises it, it self-sustaining and occurs independently of any source of influence. However, although it is the most lasting, it takes the longest to achieve. The nursing staff in the A \& $E$ unit vacillated between all these methods of adjusting to change initially, but more of them seem to have internalised their need to change by the end of the study.

Cognitive dissonance and group pressure are two of the most powerful mechanisms of attitude change. Zimbardo, Ebbesen and Maslach (1977) explain that people are social beings and are dependent on others for knowledge about themselves and the world. They say too, that pressures exit within groups which cause people to behave, feel and think alike. Cope (1981) agrees and suggests that in order to facilitate change, information should be presented to the participants in the form of perceived discrepancies from the ideal, which have been defined by the participants themselves in a group situation (eg. in a feedback meeting) where the discrepancies are seen as being contrary to their own beliefs of themselves as professionally competent. He believes that this will supply their motivation to change and keep them committed to proposed solutions derived from consensus and group discussion. Following Bowman's (1986) suggestion of allowing nursing staff to decide on what they wanted to change and encouraging their participation in the process, they were able to develop and control the change process. The fact that the majority of the staff felt that the change was relevant and essential to the improved functioning of the unit (especially the revised method of documentation) contributed to the success of the change process.

Cope (1981) mentions that there are several "rules of thumb" which can serve as a practical guide to individuals involved with projects to do with change and writes that the collection of clear and unbiased data is critical as is the perception of the need to change by nurses who are involved in the project. This point was achieved in that the data were collected without the researcher knowing what factor(s) the nursing staff would identify as being desirable to change. They were aware of the situation and conditions under which data were collected and were able to act as a check and balance regarding the accuracy of data presented to them. If data had not been accurately presented they would not have identified a need to change their behaviour.

Cope suggested that staff should be part of the problem solving process. This point was achieved in that the nursing staff read the information provided for them and participated actively in the discussions held to resolve various issues in ways that would suit them.

The researcher was sensitive to the fact that change makes large demands, emotionally, physically and socially, on all participants in the process and was careful to allow the change to take place slowly and at the nursing staffs' own pace. The researcher's continuous contact and dialogue with the staff allowed her to experience and appreciate the difficulties associated with being innovative and in implementing new ideas.

Cope suggests that positive reinforcement in the form of praise or rewards be given as frequently as possible. The researcher did not reassure or praise the nursing staff as often as they would have liked and this hampered the research process to quite a large extent, especially in the initial phases.

The fact that discussion was conducted in "on-duty" time benefitted the change process. The researcher was seen to be accommodating and whenever discussions were interrupted or had to be cancelled for any reason, the staff were always apologetic.

The researcher was able to build relationships with the nursing staff and gave them opportunities to discuss various issues relating to the change process such as their fears, anxieties and insecurities as suggested by Bowman (1986). Fillmer (in Bowman, 1986) says that it is essential that the person introducing change shows an interest in the staff. The researcher's interest in the staff as people and her interest in helping them with ordinary everyday problems also aided the process. Bowman adds that the facilitator of change requires knowledge, tact, commitment and perseverance. Towell and Harries (1979) mention that the facilitator needs to be patient and persistent in supporting the staff in their efforts to overcome difficulties. The nursing staff found that they could criticise the researcher and ask for more support or clarification of the process.

As the start of the implementation phase, basic ground-rules were laid down which stipulated that whatever was said by staff working on one shift would not be discussed with staff working on other shifts. Also, whatever was said would be confidential. Although some were not convinced that this was necessary at first, they realised how important it was later on during the "moving" phase of the research. It seems to be essential to lay down ground rules early before there are any problems since this contributes to being accepted by the participants.

Another factor which facilitated the change process was that no pressure was placed on the nursing staff for change to occur. Rather, they were informed that the research was being carried out to determine whether change would occur. They were encouraged to continue trying new interventions when they saw how beneficial minor changes were. Ultimately, they believed in the process, even though it was difficult at times, because they had made the decision of what needed to be changed, how the change was to take place and when and how the situation would be re-evaluated.

\section{Limitations of the study}

This type of study requires that the researcher be accepted and trusted by the participants who must feel that the research is worthwhile. The researcher experienced problems in this regard in that some of the nursing staff were unsure of the purpose of the research initially, and thought that the researcher had been sent by management to spy on them. One of the consequences of this was that they felt stressed and became very conscious of "doing things correctly". The researcher was fortunate in that she was able to recognise this problem and address it early on.

The participant comprehension method of collecting data had drawbacks in that it was difficult to be aware of everything that various members of the team were doing while the patient was in the unit and gaps in information had to be collected in informal discussion after the case. There was a possibility that the nursing staff would tell the researcher what they though she wanted to hear. However, the researcher is of the opinion that this did not happen often as they were very critical of their behaviour and tended to need reassurance regarding the standard of their nursing care rather than criticism.

Armitage, Champney-Smith and Andrews (1990) mention that this type of research requires years to be implemented as changes need to continue to develop and be sustained during the research period. The researcher withdrew from the unit because it was felt that the changes made were self-sustaining and that the nursing staff were far more critical of their patient care. She is aware that as staff leave and are replaced by others who may arive in the unit with prejudices regarding patients who have taken overdoses, changes that had been implemented could slowly erode. Behaviours and attitudes cannot be enforced through rules and regulations laid down by the unit or hospital management.

Another limitation of the study was the use of the attitude scale. Although the nursing staff agreed to complete the initial survey concerning their attitudes to overdose patients the response rate was fair only $(66 \%)$ and 
therefore the conciusions reached were not necessarily representative of all the nurses working in the unit. Furthermore, when the staff were asked to complete the same attitude scale at the end of the study, some of the staff who had completed the first one had left and others who had not completed the initial one completed the second. The only useful purpose that it served was that the staff became more aware of their actions and their prejudices.

One of the criticisms of action research is that the findings cannot be generalised (Degerhammer and Wade, 1991). Greenwood (1984 in Degerhammer and Wade, 1991) points out that some of the findings may be able to be generalised to other situations. Although the approach used in this study was shown to be effective, it is not known whether a similar approach in another A \& E unit would yield similar results.

\section{CONCLUSIONS}

Action research is very time consuming as it is dependent on the participants' involvement in the research process and their willingness to change behaviour and attitudes with which had felt comfortable previously. The longest time was spent during the "moving" phase of the process. The discussions involving alternative methods of working with patients who had taken overdoses and the process of carrying out decisions made in practice, were particularly time consuming.

Approximately $80 \%$ of the time spent with the nursing staff on the unit involved support and maintenance of the relationship with the researcher. Only $20 \%$ of the time was spent discussing the two change issues and working on those.

An interesting phenomenon that arose was that the nursing staff identified two problems which they said that they would like to work on simultaneously. Although the researcher was apprehensive about this decision initially, it tumed out to be serendipitous in that the designing of new, improved charts was accomplished within two weeks and they were very pleased with the difference that these new chars made to patient care. This satisfaction seemed to carry the research through the difficult times experienced when it came to implementing changes required regarding the care of patients who had taken overdoses. They knew that they had accomplished something and were able to recognise small changes that became apparent either in their own feelings of job satisfaction once they had discharged an overdose patient to the ward or in the fact that the patients and their families seemed to respond to them better in many instances. They were able to recognise during discussions, what behaviours had contributed to these feelings.

The redesigning of the charts can be seen as a concrete change, whereas the changing of the staff's attitudes and behaviour towards patients who take overdoses can be seen as a more abstract type of change. On reflection, the implementation of both a concrete change which was relatively easy, and the more time consuming abstract change, simultaneously, complemented one another. However, facilitators conducting other action research studies should be careful when assisting participants to identify problem areas that they would like to change. If the participants suggest working on two changes at the same time, it is suggested that the facilitator determine whether the problems are concrete or abstract and discuss with the participants the problems they may incur if they choose to work on two abstract problems simultaneously; working on one concrete and one abstract problem, or two concrete problems at the same time should not pose a problem.

\section{RECOMMENDATIONS}

\section{Future research}

Action research takes into account that change is an active process. There is more potential for involvement in the change process using this approach than there is for any other change strategy which might be used. It is also a method of inquiry which can bridge the gap between theory, research and practice. There is a need for this type of research to be carried out in other A \& E units throughout the country to enable nurses working in those units to observe their own practice, reflect on their observations and change their practice accordingly, in a collaborative and supportive environment.

\section{Critical incident stress debriefing (CISD)}

It became apparent during discussions with staff on the unit, that facilities (eg. a small room with a few comfortable chairs and with tea making facilities) need to be available where relatives and friends of patients who die unexpectedly can be comforted and supported away from the business of the ward and surrounding areas.

As A \& $E$ units are notoriously understaffed, it is also recommended that a chaplain or hospital social worker be available to counsel and support grieving friends and relatives. It is suggested that this person might be able to conduct the CISD meetings as they will begin to have an intimate knowledge of the A \& $\mathrm{E}$ unit and the particular way in which it functions. They have the knowledge and skills required to facilitate such a meeting. they are already seen as fulfilling a supportive role and they are bound by a professional code of ethics which includes confidentiality.

\section{Clinical Nurse Specialists}

Clinical Nurse Specialists are expected to act as change agents in their specific areas of specialization. It is suggested that action research would be an extremely useful method for them to employ when embarking on such a venture. It is recommended that action research methodology be taught to all potential Clinical Nurse Specialists so that they have a tool which they can use in a meaningful, appropriate and responsible way to facilitate change.

\section{REFERENCES}

ARMITAGE, P., CHAMPNEY-SMITH, J. ANDREWS, K. (1991): Primary nursing and the role of the nurse preceptor in changing long-term mental health care: an evaluation. Joumal of Advanced Nursing. 16: 413-422.

BARKER, W. (1992): Health visiting: action research in a controlled environment. Intemational Joumal of Nursing Studies. 29.3 251-259.

BENNIS, W.G, BENNE, K.D, CHIN, R. (1985) The planning of change. New York: Holt Rinehart \& Winston.

BOWMAN, M.P. (1986): Nursing management and education: a conceptual approach to change. London: Croom Helm.

BURNS, N., GROVE, S.K. (1987): Nursing research: conduct, critique and utilization. Philadelphia: W.B. Saunders

COPE, D.E (1981): Organisation development and action research in hospitals. Great Britain Gower

DEGERHAMMER, M. WADE, B. (1991): The introduction of a new system of care delivery into a surgical ward in Sweden. International Joumal of Nursing Studies. 28.4:325-336.

DIMOPOULOS, G.E, OWEN, R. (1993): A plan for the provision of emergency medical services local, regional and provincial. Paper presented at the Congress of the Trauma Society of South Africa, Durban, Natal

EMERGENCY NURSES ASSOCIATION (1991): Trauma nursing core course (provider) instructor manual (3rd ed.). Chicago: Award.

GHODSE, A.H., GHAFFARI, K, BHAT, A.V. GALEA, A., QURESHI, Y.H. (1986): Attitudes of bealth care professionals to people who take overdoses. International Joumal of Social Psychology. 32.4: 58-63.

HABERMAS, J. (1971): Knowledge and human interests. Boston: Beacon Press.

HOLTER, I.M., SCHWARTZ-BARCOTT, D. (1993): Action research: what is it? How has it been used and how can it be used in nursing? Journal of Advanced Nursing. 18: 298-304

McCAUGHERTY, D.(1991): The theory-practice gap in nurse education: its causes and possible solutions. Findings from an action research study. Journal of Advanced Nursing. 16 1055-1061.

McNIFF, J. (1988): Action research: principles and practice. London: Macmillan Education.

POLIT, D.F., HUNGLER, B.P. (1993): Nursing research: principles and methods (2nd ed.) Philadelphia: J.B. Lippincott

REILLY, D.K., RAY, J.E., DAY, R.O. WODAK, A., O'CONNOR, D. THOMPSON, J. (1987): Classification of overdose/self poisoning presentations to an accident and emergency department International Journal of Addiction. 22.10: $941-955$

SHEEHAN, J. (1990): Investigating change in a nursing context. Journal of Advanced Nursing. 15: 819-824 
TOWELL, D., HARRIES, C. (1979): Innovation in patient care. Great Britain: Croom Helm.

VAN DER MERWE, C.J. (1991): Trauma in the South African community. Trauma and Emergency Medicine. May/June: 325

VAN DER SPUY, J.W. (1990): Towards better trauma care. Trauma -The Journal of Accident and Emergency Medicine. Sept/Oct: 180-181

VAN DER SPUY, J.W. (1993): Trauma in South Africa: some findings and perspectives. Trauma Yearbook '93: 4-9
WEBB, C. (1989): Action research: philosophy, methods and personal experiences. Journal of Advanced Nursing. 14: 403-410.

WEBB, C., ADDISON,C., HOLMAN, H., SAKLAKI, B., WAGNER, A. (1990): Self-medication for elderly patients. 86.16: 46-49.

ZIMBARDO, P.G., EBBESEN, E.B. MASLACH, C. (1977): Influencing attitudes and changing behaviour. (2nd ed.). Philippines: Addison-Wesley.
Diana Kerr RN.RM.M.Soc Sc (Natal) UNIVERSITY OF NATAL

Department of Nursing DURBAN 